\title{
Criminología verde, esfuerzo de aplicación de las regulaciones sobre vida silvestre en México entre el 2006 y 2020
}

\section{Green criminology, wildlife law enforcement in Mexico between 2006 and 2020}

Jesús Ignacio Castro Salazar*

Recibido: 10-12-2021

José Luis Carpio-Domínguez**

Aceptado: 13-01-2022

Inés Arroyo-Quiroz***

\section{Resumen}

Los crímenes contra la vida silvestre ponen en riesgo a las especies y son un problema a nivel global. La criminología verde analiza estrategias para minimizar y evitar daños a la vida silvestre y reconoce que la aplicación efectiva de las leyes es crucial para la conservación de las especies. En México, la legislación tiene competencias en vida silvestre para la atención y prevención de la criminalidad ambiental. El presente estudio explora en México los esfuerzos de aplicación

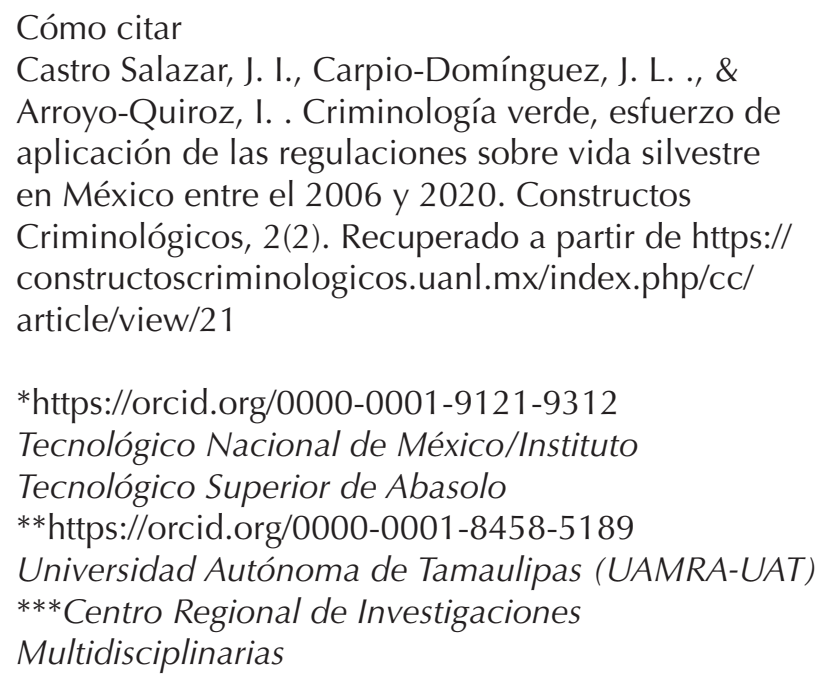

de la ley ambiental, en lo penal y administrativo, en materia de vida silvestre en entre el 2006 y 2020; con enfoque particular en las acciones de las autoridades competentes, la Fiscalía General de la República (FGR) y la Procuraduría Federal de Protección al Ambiente (PROFEPA). Se hace un análisis estadístico de cifras oficiales de delincuencia ambiental durante el periodo y se complementa con entrevista a inspectores que aplican la ley. Como parte de los resultados se identificó que los esfuerzos de aplicación de la ley ambiental son escasos y se muestra un descenso en las frecuencias durante en el periodo de estudio. Se evidencia el predominio de las sanciones administrativas frente a las penales.

Palabras clave: criminología verde; prevención institucional; aplicación de la ley; conservación de vida silvestre.

\section{Abstract}

Crime against wildlife puts species at risk and is a global problem. Green criminology analyzes strategies to minimize and avoid 
damage to wildlife and recognizes that effective enforcement of laws is crucial for the conservation of species. In Mexico, the legislation has competences in wildlife for the attention and prevention of environmental crime. This study explores in Mexico the law environmental enforcement, criminal and administrative law, regarding wildlife between 2006 and 2020; with a particular focus on the actions of the competent authorities, the Office of the Attorney General of the Republic (FGR) and the Federal Attorney for Environmental Protection (PROFEPA). A statistical analysis of official figures on environmental crime is applied during the period and is complemented by interviews with inspectors who apply the law. As part of the results, it was identified that environmental law enforcement is scarce and a decrease in frequencies is shown during the study period. The predominance of administrative sanctions over criminal ones is evident.

Key Words: green criminology; institutional prevention; law enforcement; wildlife conservation.

\section{INTRODUCCIÓN}

Lasteoríasyperspectivasutilizadasencriminología para avanzar en el conocimiento sobre la ley, autoridades de aplicación, mecanismos de sanción, prevención e intervención, aportan a la comprensión de las dinámicas entre el humano y el ambiente (Maxwell, S. y Maxwell, C., 2020). Durante la última década, con la expansión de la criminología verde, la atención criminológica retoma crímenes ecológicos y ambientales (Lynch, M., 2018). La criminología verde estudia en vida silvestre, entre otras cuestiones, los crímenes (incluyendo los que no aparecen en la ley), las leyes (incluidas las prácticas de aplicación y sentencia) y la regulación (sistemas de derecho administrativo, civil y penal diseñados para proteger especies) (White, R., 2007; Boratto, R. y Gibbs, C., 2019; Nurse, A., 2020). Los crímenes contra vida silvestre constituyen sólo una dimensión del problema, pues la aplicación de la ley también es importante (Elliott, L., 2007). La aplicación efectiva de las leyes es crucial para la gestión y conservación (Fang, L., Hipev, K. y Kilgour, D., 1994), al ser un subconjunto de actividades que se utilizan para hacer que la sociedad o el individuo regulado cumplan o vuelvan a cumplir, de manera más forzada, la ley (Pink, G., 2013).

Los crímenes ambientales suelen ser poco prioritarios en sistemas de justicia penal y de poca preocupación pública en seguridad, a pesar de tener el potencial de causar impactos sociales amplios y muertes (Nurse, A., 2020). A diferencia de los delitos tradicionales contra la propiedad y los bienes, los crímenes ambientales suelen tener efectos duraderos e irreversibles; lo que plantea interrogantes respecto a la eficacia de los sistemas judiciales para enfrentar a los infractores ambientales (Nurse, A., 2020). El hecho de que los delitos contra la vida silvestre vayan en aumento a nivel global, sugiere que las respuestas políticas han tenido un éxito limitado para prevenir esos delitos, y surgen preguntas sobre los por qué (Horne, D., 2013). Es importante indagar en la organización y aplicación de la ley, situaciones que, de ser poco efectivas, aportaría al deterioro de los ecosistemas y sus componentes (Lynch, M., 2019). 
Existe la creencia que sólo lo definido por el derecho penal como delito puede clasificarse como delito ambiental o "delitos verdes" (Nurse, A., 2020). También se piensa que el propósito del derecho penal es quitar la idea de que las multas civiles o administrativas son una licencia para contaminar (Bellew, S. y Surtz, D., 1997). Parece que el enjuiciamiento penal es la mejor esperanza para quienes creen que el gobierno debe redoblar esfuerzos para preservar la naturaleza, pero puede implicar procesos largos y poco prácticos (Pink, G., 2013; Steinzor, R., 2016). Una respuesta integral y equilibrada a los delitos ambientales debe incluir recursos administrativos, civiles y penales, y las autoridades deben trabajar juntas para garantizar que las leyes ambientales se apliquen equitativamente (Epstein, J., 1995), además, coordinar operaciones de aplicación de la ley es clave para combatir y monitorear el comercio, legal e ilegal, de vida silvestre (Wyatt, T., 2014).

Si bien la aplicación de la ley es una solución a corto plazo para combatir los delitos contra la vida silvestre (Bennett, 2011 en Boratto, R. y Gibbs, C., 2019), una regulación aplicada de manera agresiva para prevenir daños es buena opción (Steinzor, R., 2016). El estudio European Network of Prosecutors for the Environment (2018) recomienda que la política de aplicación de la ley en temas ambientales debe basarse en una visión de aplicación de la ley pública, es decir, una visión que abarque lo penal y administrativo, en un sólo sistema de aplicación.

A pesar de que los delitos contra la vida silvestre representan una amenaza también para los humanos, son tratados de manera deficiente e inconsistente por los sistemas de justicia contemporáneos (Nurse, A., 2020), la aplicación de la ley es blanda (European Union Agency for Law Enforcement Cooperation [EUROPOL] 2015; Ayling, J., 2017) y se sabe poco sobre cómo los Estados responden, con pocos ejemplos que contribuyan a observar los esfuerzos públicos para cumplir la ley (Tsioumani, E. y Morgera, E., 2010; Lynch, M., 2018). Aunque actualmente existe más conciencia sobre la gravedad de los crímenes contra la vida silvestre, el análisis de esos crímenes dentro de la aplicación de la ley es reciente, especialmente en países en desarrollo (Moreto, W., 2015), por lo que es importante describir y examinar los procesos de implementación de la vigilancia de la naturaleza (Gibbs, C., McGarrell, E. y Sullivan, B., 2015).

En México, la aplicación de la ley ambiental es nueva en la perspectiva criminológica, por lo que se desconocen muchos datos, y pocos estudios emplean variables criminológicas (Carpio-Domínguez, J., et al., 2018a). Las leyes ambientales suelen considerarse "sin víctimas" y, por lo tanto, de baja prioridad por las autoridades, por lo que las leyes suelen ser inadecuadas, con penas bajas y aplicaciones laxas (White, R., 2007; Ayling, J., 2017; Boratto, R. y Gibbs, C., 2019). Con base en lo anterior, el presente trabajo explora los esfuerzos de aplicación de la ley ambiental en el país, en lo penal y administrativo, en materia de vida silvestre entre el 2006 y 2019; con enfoque particular a las acciones de las autoridades competentes, la Fiscalía General de la República (FGR), en lo penal, y la Procuraduría Federal de Protección al Ambiente (PROFEPA), 
en lo administrativo. Se indaga en cómo las autoridades responsables de aplicar la ley responden a los delitos y crímenes de vida silvestre sobre las que tienen jurisdicción.

\section{APLICACIÓN DE LA LEY DE VIDA SILVESTRE EN EL MARCO DE LA CRIMINOLOGÍA VERDE}

La naturaleza es crucial para el humano, por lo tanto, su degradación y contaminación ponen en riesgo su seguridad (Elliott, L., 2007; Fagan, M., 2017). La seguridad ambiental tiene varios significados, pero se puede determinar si una perturbación es un problema de seguridad basado en tres componentes: 1) si los impactos de la perturbación ambiental son una amenaza a la seguridad nacional; 2) si la amenaza e impactos podría causar problemas políticos internacionales y malestar social nacional; y 3) si el aparato de seguridad nacional institucional y cultural puede brindar una respuesta eficaz a la amenaza; y de ser así, si a todas o sólo a algunas (Allenby, 1998b en Allenby, R., 2000; Floyd, R., 2008). La seguridad ambiental puede analizarse en componentes, como la seguridad biológica, compuesta por las diversas comunidades biológicas, e implica mantener la salud y estabilidad de los sistemas biológicos críticos, cuya interrupción crearía implicaciones de seguridad nacional (Allenby, R., 2000).

Los delitos y crímenes contra el ambiente y vida silvestre son temas transversales que une campos como la gestión, conservación y criminología (Moreto, W., 2015). Tienen implicaciones económicas, sociales y de seguridad negativas a corto y largo plazo y, por tanto, deben considerarse como una amenaza directa e indirecta para el humano (Nurse, A., 2020). En el caso de vida silvestre, los crímenes y delitos son un riesgo para la seguridad porque que amenaza a las especies y sus poblaciones, extingue especies, altera los ciclos biológicos y cadenas tróficas, afecta los hábitats naturales y socava la seguridad social y económica de los países (Nellemann, C., et al., 2016 y 2018; Carpio-Domínguez, J., 2021).

El "delito ambiental" no está universalmente definido, pero puede emplearse para describir las actividades ilegales que dañan el ambiente (Nellemann, C., et al., 2016). En la perspectiva legal, el delito es toda conducta antijurídica sancionada por los códigos penales, mientras que para la criminología el concepto de conducta antisocial (crimen) comprende aquellas conductas que atentan contra el bien común, sin considerar si los marcos legales las sancionan o no (Rodríguez-Manzanera, L., 2015). En ese último sentido, White propone el termino daño (harm) en el marco de la victimología verde y justicia ecológica, y considera que: 1) las víctimas de daños ambientales incluyen a toda la biosfera; 2) el daño ambiental es un problema regional, nacional y mundial; y, 3) el impacto del daño ambiental puede ser a corto, mediano o largo plazo, y tener impactos sociales inmediatos y/o duraderos (Hall, M. y Varona, G., 2018, p. 114). En lo penal, el delito ambiental es una violación de la ley que, para clasificarse como delito ambiental, debe estar sujeto a enjuiciamiento y sanciones penales; desde esa perspectiva, se limita a infracciones ambientales consideradas más graves, omite infracciones menores o asociadas, como la infracción de permisos u infracciones técnicas que aparentemente no 
causan daños tangibles, y otras actividades que escapan a la atención de los legisladores (Nurse, A., 2020).

Desde el enfoque de la criminología verde, el daño ambiental se considera en sí mismo un crimen(social y ecológico), independientemente de su estatus o clasificación legal (RodríguezManzanera, L., 2015); es decir, si se daña el ambiente o vida silvestre, es un "crimen" (White, R., 2010 y 2013; Carpio-Domínguez, J., et al. 2018a; Nurse, A., 2020). ${ }^{1}$ Que una conducta no se defina como conducta delictiva, no significa que no haya ningún daño, independientemente si se encuentra definido en la ley (Lynch y Stretesky, 2014, p. 7 en Nurse, A., 2020, p. 9). Tanto delitos como crímenes contra la vida silvestre, incluidas sus causas, relaciones, distribución, control y daño, son áreas de estudio de la criminología verde (Hall, M., 2014; Lynch, M., 2019).

La criminología verde apuesta por promover sistemas de justicia e investigaciones que vayan más allá de la concentración en los sistemas de justicia penal y el uso del derecho penal (Nurse, A., 2020). Permite el estudio del derecho penal y de las leyes ambientales, incluye el daño ambiental generalizado y el abuso de animales no humanos (Nurse, A., 2020). Argumenta que el estudio de las violaciones a la ley ambiental es limitado (White, R., 2008 en Gibbs, C., et al. 2010). Un crimen verde o ecológico incluye el estudio de daños contra los animales

1 Por ello, y considerando que en México el término "crimen" incluye los "daños", el presente estudio empleará el término "crimen" para referirse también al "daño" causado a la vida silvestre. no humanos cometidos por instituciones poderosas (por ejemplo, gobiernos, empresas transnacionales) y por personas en general (Beirne y South, 2007 en Lynch, 2019, p. 4). Además, estudia temas y problemas que incluyen mejoras en la prevención, el impacto, así como las formas de aplicación de la ley y reglas asociadas con el daño ambiental (White, R., 2010; Brisman, A. y South, N., 2012).

En la ecología política, pese a analizar temas de conservación ecológica y biopolítica, la aplicación de la ley se utiliza poco, sobre todo en crímenes de vida silvestre, y de no emplearse, podría invisibilizar una comprensión crítica de las formas de poder asociadas con la vigilancia institucional (Massé, F., 2019). La ecología política se beneficiaría de la criminología verde, pues no sólo necesita interrogar críticamente y dar cuenta del privilegio de cierto conocimiento e ideas sobre la conservación, sino también debe deconstruir los discursos del crimen y la vigilancia que convergen en el crimen de conservación (White, R., 2013; McGarrell, E. y Gibbs, C., 2014; Massé, F., et al., 2020).

Lo anterior complementa y contribuye a la perspectiva de la criminología verde mediante la integración de teoría y métodos propios de la criminología, la gestión de recursos naturales y la formulación de políticas criminológicas que aportan a la comprensión del comportamiento delictivo, la aplicación y el cumplimiento de la ley y la interacción entre "la ley en los libros" y la "ley en acción" (McGarrell, E. y Gibbs, C., 2014), con base en preocupaciones criminológicas que incluyen la aplicación regulatoria desde la legislación (White, R., 2013; Gibbs, C., et al. 2010; McGarrell, E. y 
Gibbs, C., 2014) y también desde la aplicación preventiva.

La criminología contribuye a la investigación en la aplicación de la ley ambiental con el marco sistemático que la disciplina utiliza en las políticas y prácticas generales de aplicación (Maxwell, S. y Maxwell, C., 2020). Hasta ahora, la principal respuesta de los Estados y las organizaciones internacionales hacía los delitos ambientales es fortalecer la aplicación de la ley (Ayling, J., 2017). Con una legislación que describe una amplia gama de delitos, que incluye comportamientos perjudiciales para el ambiente, así como delitos contra el sistema de control (Nilsson, A., 2011; White, R., 2014).

La mayoría de las acciones institucionales para atender los delitos ambientales están vinculados a acciones de aplicación de la ley ambiental administrativa, particularmente aborda irregularidades que a menudo se clasifican como faltas accidentales y resulta en una variedad de infracciones (EUROPOL, 2015; Nurse, A., 2020). Eso puede apreciarse en las investigaciones y enjuiciamientos de los delitos ambientales, así como en las funciones de las autoridades administrativas de ejecución (Nilsson, A., 2011).

La aplicación de la ley ambiental está vinculada con proteger y preservar la integridad ecológica, por lo que, desde el punto de vista de los resultados ambientales, se concentra más en interrumpir los delitos para disminuir su ocurrencia, y no tanto en la detención y enjuiciamiento (Barrett, S., y White, R., 2017). La aplicación involucra la verificación de la autoridad reguladora mediante la realización de inspecciones y monitoreos en el sitio para garantizar que se cumpla la ley (Pink, G., 2013). El proceso de inspección lo realiza una organización o persona (inspector) que decide si una organización o persona (inspeccionado) se comporta según lo establecido en ley u otro requisito formal (Fang, L., Hipev, K. y Kilgour, D., 1994). La inspección de las autoridades reguladoras es vital, al estar vinculada a detectar acciones delictivas (EUROPOL, 2015). Estudiar los delitos ambientales requiere abordar no sólo estatutos legales, sino también los mecanismos de aplicación de la ley que definen y controlan (Lynch, M., 2019).

Si bien los gobiernos promulgan leyes con estándares ambientales enfocados a la protección, la mera existencia de leyes rara vez es suficiente para asegurar su éxito, existen problemas de aplicación relacionadas con el esfuerzo humano (Fang, L., Hipev, K. y Kilgour, D., 1994). Los problemas también suelen estar relacionados con la eficacia de aplicación, como la capacidad, coordinación y jurisdicciones constitucionales de las dependencias en la materia (Jaffe, L., 1963; Ayling, J., 2017). La falta o capacidad limitada están entre las principales barreras para lograr la efectividad de las regulaciones, impide que la autoridad haga cumplir la ley de vida silvestre (Tsioumani, E. y Morgera, E., 2010). A menudo, las dependencias de aplicación de la ley ambiental tienen capacidades limitada de recursos humanos y financieros (EUROPOL, 2015; Castro-Salazar, J. y Luyando-Cuevas, J.; Castro-Salazar, J. 2021).

Otro problema son las jurisdicciones en vida silvestre, las leyes que se formulan en 
jurisdicciones determinadas e incluyen el derecho internacional, federal, estatal y regulaciones locales (White, R., 2007). En casi todas las jurisdicciones existen diversas dependencias $u$ organismos que hacen cumplir la legislación de vida silvestre (ejemplo, policía, agencias de aduanas, funcionarios de puertos y aeropuertos, etc.), con competencias específicas en delitos ambientales (EUROPOL, 2015; Ayling, J., 2017). Dependiendo de la ciudad o Estado, puede existir una diversidad de leyes, dependencias y personal de aplicación, incluso la policía tendrá funciones diferentes (White, R., 2007; Nurse, A., 2020). Además, existen factores operativos y de política que dan forma a las respuestas de aplicación, por ejemplo, según las jurisdicciones, las dependencias administrativas pueden investigar los delitos ambientales de manera independiente o junto con la policía (Pink, G., 2013; EUROPOL, 2015).

La aplicación de la ley ambiental podría tener un enfoque mixto (administrativo, civil y penal) en un país o un enfoque penal estricto en otro; dependiendo del nivel percibido del problema, la influencia del lobby, los grupos políticos y la naturaleza del sistema de justicia (Nurse, A., 2020). Eso involucra una base legislativa con una superposición de recursos (administrativos, civiles y penales) (Nurse, A., 2020). En esa diversidad, los grupos delictivos organizados son expertos en aprovechar las diferencias entre regulaciones y jurisdicciones, por lo que, aunque parece difícil, se requiere coordinar esfuerzos entre jurisdicciones (White, R., 2010; Ayling, J., 2017).

La criminología verde debe trasladar la regulación ambiental más allá de la tradicional dicotomía "penal versus civil/administrativa" (Hall, M., 2014). Desde la criminología verde es posible analizar no sólo cuestiones de delito según la definición legalista del derecho penal, sino también cuestiones relativas al uso de los sistemas administrativo, civil y penal (Nurse, A., 2020). Se piensa que la justicia penal tradicional, que se centra en la infracción y el castigo individualista, puede ser inadecuada para abordar el problema de los delitos ambientales, al existir problemas en la clasificación e investigación de dichos delitos (Nurse, A., 2020). Son necesarias alternativas al uso de la justicia penal como solución para abordar los delitos ambientales, dadas las características del derecho penal y su perspectiva de aplicación legal de detección, aprehensión y castigo en lugar de reparar el daño y que generalmente sólo tiene lugar una vez producido el delito; de ahí que las sanciones penales por sí solas no pueden abordar de manera adecuada los problemas ambientales de la sociedad (Hall, M., 2014; Nurse, A., 2020).

El derecho penal puede ser complementado con métodos administrativos de aplicación de la ley y el empleo de sanciones civiles ambientales, que ofrecen ventajas sobre la aplicación penal y sus estándares ambientales (Bell et al., 2013, p. 265 en Hall, M., 2014; Hall, M., 2014). Pero también considerando las limitantes de los otros sistemas. Los principios civiles se relacionan a cuando una persona causa un daño al patrimonio de otra, pero sólo tiene aplicación para daños en bienes y a personas en individual, y presenta inconvenientes cuando se afecta la biodiversidad (López, P. L. y Ferro, A., 2006; Chávez, B.F., 2009; Pink, G., 2013). 
Los principios administrativos se relacionan con violaciones a leyes administrativas establecidas por instituciones públicas, cuyas sanciones pueden ser multas, suspensión de actividades, revocación de autorizaciones, concesiones o permisos (López, P. L. y Ferro, A., 2006; Chávez, B.F., 2009; Pink, G., 2013), y son consideradas infracciones menores que pueden verse como una "opción blanda" (Pink, G., 2013). Así, las actividades de aplicación dependen de factores como la jurisdicción, estructuras organizativas y la capacidad y composición de las dependencias (Pink, G., 2013). Una respuesta integral y equilibrada a los delitos ambientales debe incluir recursos administrativos, civiles y penales, las dependencias deben trabajar juntas para garantizar que las leyes y regulaciones se apliquen de manera equitativa (Epstein, J., 1995).

\section{METODOLOGÍA}

El presente estudio se aborda desde un enfoque metodológico de corte exploratorio, centrado en explorar cómo ha sido aplicada la ley ambiental en México, desde lo penal y administrativo, en materia de vida silvestre durante el periodo 2006 y 2020 (El periodo se basa en la información pública disponible y en la proporcionada por las autoridades competentes); con un enfoque particular a las acciones de las autoridades competentes, la FGR, en lo penal, y la PROFEPA, en lo administrativo. De manera que permita comprender cómo responden a los delitos y crímenes contra la vida silvestre las autoridades responsables de aplicar la ley ambiental. Como justificación teórico metodológico, los estudios exploratorios sirven para indagar en un fenómeno del cual, no se han generado suficientes conocimientos por falta de investigaciones (Flick, U. 2015), permitiendo buscar preguntas y respuestas (Penalva-Verdú, C., et al., 2015) y aporta a la validez descriptiva del fenómeno estudiado (Maxwell, J., 1992).

El estudio analiza las variables: periodo de estudio, fuero de competencia, delitos y acciones implementadas por las dependencias (FGR y PROFEPA) (Cuadro 1).

Cuadro 1. Variables de análisis en el estudio de la aplicación de la ley de vida silvestre en México

\begin{tabular}{|c|c|}
\hline Variables & Subvariables \\
\hline Periodo & 2006-2020 \\
\hline Fuero & Federal \\
\hline Sistema de Justicia & Penal y Administrativo \\
\hline Delitos & $\begin{array}{c}\text { Los contenidos en el Código Penal Federal y la Ley } \\
\text { General de Vida Silvestre y su Reglamento }\end{array}$ \\
\hline Acciones institucionales & $\begin{array}{c}\text { Averiguaciones previas, personas detenidas y } \\
\text { consignadas, operativos de vigilancia e inspección } \\
\text { y aseguramientos de especies. }\end{array}$ \\
\hline
\end{tabular}

Fuente: los autores 
De manera complementaria, se realizaron entrevistas semiestructuradas a seis servidores públicos de la PROFEPA que realizan actividades de inspección y aplicación de la legislación en vida silvestre en el país. Las entrevistas se fundamentan en la complementariedad del método mixto, de manera quepermiten profundizar y complementar la información analizada en los datos estadísticos considerados en el Cuadro 1.

Para identificar las jurisdicciones y los procesos, se analiza el contenido de la Constitución, los Códigos Penales y las leyes en México buscando las competencias, artículos vinculantes, preceptos y las autoridades competentes en el tema de vida silvestre. Para conocer el número de acciones hacía los delitos y crímenes, el estudio utiliza datos obtenidos de los esfuerzos realizados por las autoridades encargadas de aplicar la legislación en vida silvestre en el sistema penal y administrativo en México.

Los datos fueron recabados de bases de datos de acceso público Secretariado Ejecutivo del Sistema Nacional de Seguridad Pública (2021) y a través de solicitudes de información a la PROFEPA y la FGR, según lo estipulado en la Ley Federal de Transparencia y Acceso a la Información (2017) (artículos 123 y 124). Los datos solicitados son los siguientes: En el sistema penal: 1) averiguaciones previas iniciadas; 2) personas detenidas al inicio de las averiguaciones; y 3) personas consignadas dentro de las averiguaciones. En el sistema administrativo: 1) inspecciones en vida silvestre y recursos marinos y 2) operativos en vida silvestre y recursos marinos. Con ayuda del software QGIS, se analizó la distribución de los delitos en materia de vida silvestre, por categoría y tendencia de las frecuencias.

Por otra parte, las entrevistas fueron aplicadas durante el periodo junio de 2018 a mayo de 2019 y estuvieron orientadas a explorar la percepción y experiencias de los inspectores de la PROFEPA acerca de la aplicación de la ley en materia de vida silvestre en México.

\section{RESULTADOS Y DISCUSIÓN}

\section{Jurisdicciones penales y administrativas en vida silvestre en México}

Las jurisdicciones en México para regular la vida silvestre están presentes en la Constitución Política de los Estados Unidos Mexicanos (CPEUM), vigente al 2021. El artículo 27 de la Constitución establece que la explotación, uso y aprovechamiento de vida silvestre sólo podrá realizarse mediante concesiones, otorgadas por el Ejecutivo Federal, de acuerdo con las reglas y condiciones que establezcan las leyes. Por lo que las autoridades estatales o locales, no tienen atribuciones salvo que establezcan acuerdos con el gobierno federal.

En el sistema penal federal, el Código Penal Federal (CPF), vigente al 2021, contiene preceptos legales para sancionar delitos contra la vida silvestre, del artículo 414 al 420 Bis (Cuadro 2). Dichos preceptos están relacionados con introducir al territorio Nacional o traficar ejemplares de vida silvestre (artículo 417); o con capturar, dañar, privar de la vida, trasportar y almacenar especies específicas (como tortugas o mamíferos marinos, especies acuáticas declaradas en veda, abulón, camarón, pepino de mar y langosta) (artículo 420, fracciones I, II 
y II Bis). En general, las sanciones por incumplir la legislación penal contra la vida silvestre oscilan entre seis meses a diez años de prisión; incluso, establece como pena realizar trabajos a favor de la comunidad. Condenas que pueden ser "bajas" si se toman en cuentan los posibles daños que pueden causar e incluso poner en riesgo la seguridad de las personas.

Cuadro 2. Legislación penal en materia de vida silvestre en el Código Penal Federal Mexicano

\begin{tabular}{cc}
\hline & Nomenclatura \\
\hline Flora y Fauna silvestre & Artículos 414, 415 (fracciones I, II y III) y 416 \\
\hline Fauna silvestre & Artículos 417, 420 \\
\hline Flora silvestre & Artículos 417, 420 (fracciones IV y V) \\
\hline Flora o Fauna exótica & Artículos 420 Bis (fracción III) \\
\hline Acciones institucionales & $\begin{array}{c}\text { Averiguaciones previas, personas detenidas y } \\
\text { consignadas, operativos de vigilancia e inspección } \\
\text { y aseguramientos de especies. }\end{array}$ \\
\hline
\end{tabular}

Fuente: los autores

En el sistema administrativo federal existen tres regulaciones que contienen preceptos legales sancionables por crímenes contra vida silvestre: la Ley General del Equilibrio Ecológico y Protección al Ambiente (LGEEPA), la Ley General de Vida Silvestre (LGVS) y el Reglamento de la LGVS, vigentes al 2021. Además, existe la Norma Oficial Mexicana 059 (NOM-059-
Semarnat-2010) que contiene listados de las especies o poblaciones de México en riesgo (basada en el Convention on International Trade in Endangered Species of Wild Fauna and Flora -CITES-). Pero son la LGVS y su Reglamento las que contienen los principales y más importantes preceptos administrativos sancionables en vida silvestre (Cuadro 3).

Cuadro 3. Legislación penal en materia de vida silvestre

\section{Legislación}

LGVS

\section{Nomenclatura}

Artículos 27, 27 bis 1, 28, 30, 32, 33, 34, 35, 36, 39, 40, 42, 51, 52, 53, 54, 55, 55 bis, 60 bis, 60 bis 1,60 bis 2, 73, 76, 78, 78 bis, 79, 83, 84, 85, 86, 90, 94, 96, 97, 98, 99,

101,102 y 103 
En lo administrativo se identifican una diversidad de conductas sancionables relacionadas a la vida silvestre y a los sistemas de control. Por ejemplo, la LGVS contiene artículos sobre el aprovechamiento de fauna silvestre (art. 30), traslado de ejemplares vivos (art. 31 y 52), exhibición de ejemplares (art. 32), entrenamiento de ejemplares de fauna (art. 34), comercialización (art. 35), legal procedencia (art. 51), exportación e importación de ejemplares, partes y derivados (art. 53, 54 y 55), liberación de ejemplares (art. 79), colecta de ejemplares con fines científicos (art. 97), por mencionar algunos. Las sanciones por incumplir la legislación administrativa incluyen: a) amonestaciones estrictas, b) multas, c) suspensiones de permisos, d) revocaciones de autorizaciones, e) clausuras de instalaciones en las que se desarrollan las actividades, f) arresto administrativo hasta por 36 horas, g) decomiso de ejemplares, partes y derivados de vida silvestre y h) pago de gastos al depositario de los ejemplares. Sobre la amonestación escrita, la multa y el arresto administrativo, estas podrán ser conmutados por trabajo comunitario en actividades de conservación de la vida silvestre (art. 123 de la LGVS). De ahí que se consideré que las sanciones administrativas son "blandas", tal como lo han reportado otros estudios (White, R., 2007; Ayling, J., 2017; Boratto, R. y Gibbs, C., 2019).

En México, existe una mayor cantidad de preceptos y temas sancionables en lo administrativo que en lo penal. Lo administrativo contempla una mayor heterogeneidad de delitos, incluye sanciones tanto contra la vida silvestre como al sistema de control. Pero las sanciones más severas son en lo penal, sólo por incluir prisión de máximo 10 años, sin embargo, no se obliga a reparar los daños y lo deja a que sea voluntario para reducir la pena. Mientras que la legislación administrativa obliga a las personas que dañen a la vida silvestre, sin perjuicio de sanciones penales o administrativas procedentes, a reparar los daños causados, conforme a la legislación civil aplicable. Situación que coincide con lo mencionado por Hall, M., (2014) y Nurse, A., (2020), sobre que el derecho penal se enfoca más a la detección y castigo en lugar de reparar el daño.

Respecto a la colaboración entre sistemas, el sistema administrativo señala que la autoridad administrativa está facultada y obligada a iniciar acciones penales, ante la FGR, cuando tenga conocimientos de actos, hechos u omisiones conforme a la ley (art. 182 y 202 de la LGVS). Al respecto, en las entrevistas se identificó que los inspectores administrativos de PROFEPA mencionan que realmente son pocas las veces que ese precepto se cumple, sobre todo por una falta de interés del sistema penal para tratar crímenes contra la vida silvestre. Por último, el sisma civil mexicano, a través del Código Civil Federal, no contiene preceptos en temas ambientales, biodiversidad o vida silvestre.

\section{Esfuerzo de aplicación del derecho penal}

Una vez identificadas las jurisdicciones en vida silvestre, se analizan los esfuerzos de aplicación de las regulaciones aplicables, en lo penal y en lo administrativo. Al comparar temáticas delictivas en lo penal, se identifica una variedad de incidencias determinadas por 
el tipo de violación al CPF (Gráfica 1). ${ }^{2}$ Del No significa que existan menos delitos 2006 a octubre del 2020, se registraron un total ambientales, quizás refleja falta de interés al de 21,045 incidencias en el tema ambiental (el tema por las autoridades penales, Por ejemplo, segundo con menos averiguaciones en México). a diferencia de otros delitos, como a la salud, la El número de incidencias ambientales penales información pública del Secretariado Ejecutivo investigadas incluso están por debajo de los delitos electorales $(24,557)$ y patrimoniales $(315,853)$ (Gráfica 1), delitos de menor impacto. del Sistema Nacional de Seguridad Pública no disgrega los delitos ambientales por temática especifica. También puede deberse a que no Gráfica 1. Incidencias delictivas a Código Penal Federal por tipo de delito del 2006 al 2020

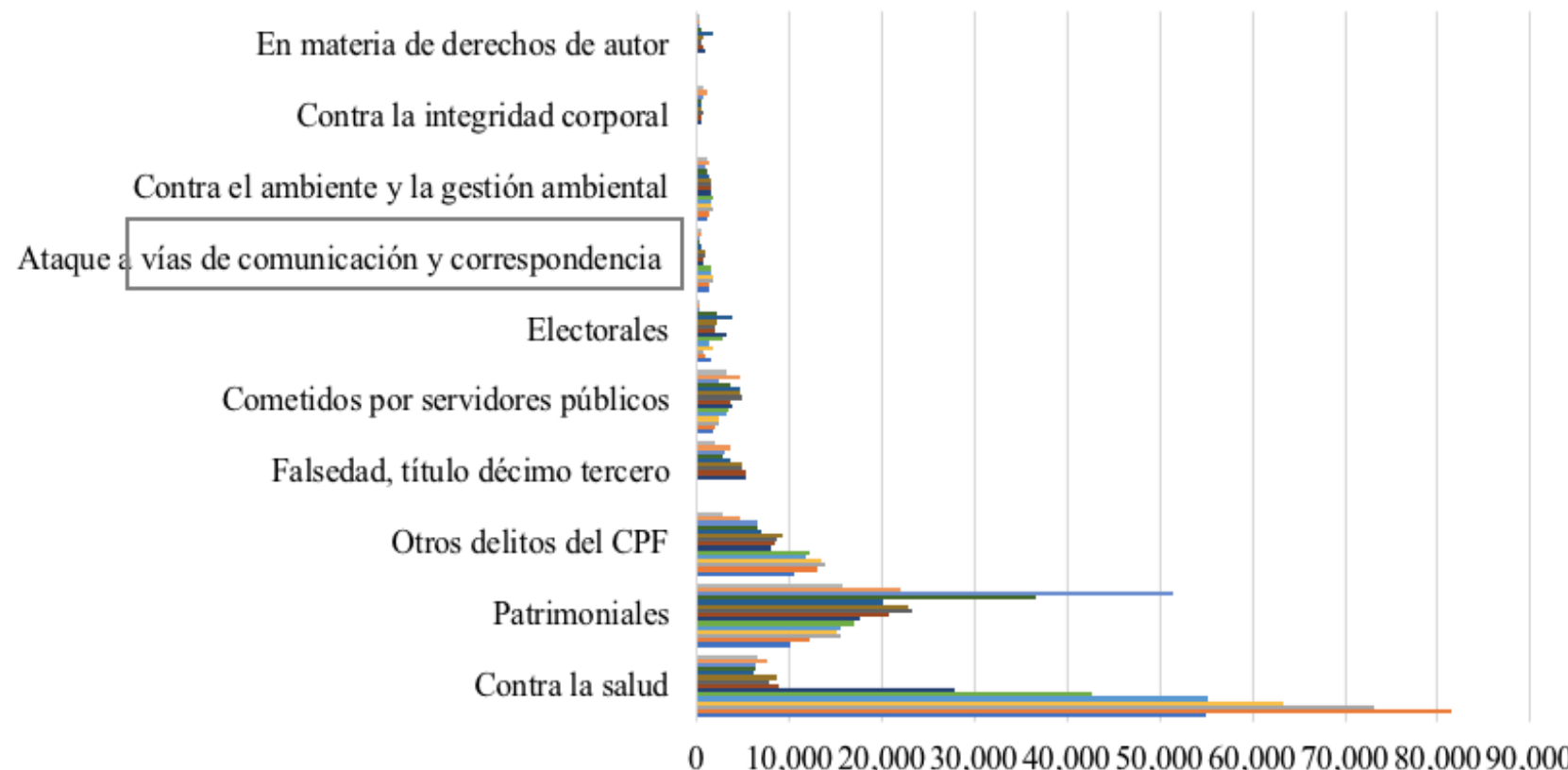

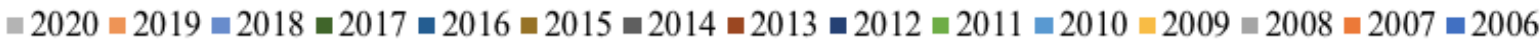

Fuente: los autores con información obtenida de la Secretariado Ejecutivo del Sistema Nacional de Seguridad Pública (2020). Nota: Sólo existen datos de los delitos contra la integridad corporal, en materia de derechos de autor y falsedad a partir del año 2011.

todos los delitos se reportan ante las autoridades, lo que se conoce como cifra negra (Sozzo, M.,

2 La incidencia delictiva es la presunta ocurrencia de delitos registrados en averiguaciones previas iniciadas o carpetas de investigación, reportadas por la FGR en el fuero federal (Secretariado Ejecutivo del Sistema Nacional de Seguridad Pública, 2021). 2003), esto representa que muchos delitos no son registrados por las instituciones gubernamentales, por lo que difícilmente son parte de las estadísticas oficiales. En el caso de México, la cifra negra sobre delitos asciende al $88.8 \%$, sólo se reporta el 11.2 
$\%$ de los delitos (Instituto Nacional de Estadística y Geografía [INEGI], 2020), y se estima que en delitos ambientales la cifra negra puede ser mayor. De acuerdo con los inspectores entrevistados, las autoridades penales dan mayor importancia a otros temas delictivos, sobre todo relacionados con salud humana, seguridad pública y en contra del patrimonio, y prestan menos interés a delitos contra el ambiente, incluyendo la vida silvestre. Salvo casos cuando los delitos ambientales están relacionados con delitos de seguridad pública (p. ej. cuando se reportan casos de posesión de animales exóticos a integrantes del crimen organizado) (Carpio-Domínguez, J., et al., 2018b).

Cuando la policía atiende reportes de homicidio, autos robados, etc., y han encontrado tigres en jaulas, reciben la orden de dejar todo allí porque es propiedad de alguien pesado [del crimen organizado] sólo se retiran y ya, son nos notifican a nosotros (Inspector 4-PROFEPA, comunicación personal, 25 de abril de 2019).
Incluso, en lo penal, entre el 2006 y 2018, desde el 2012 se ha observado una tendencia decreciente de averiguaciones previas, de personas detenidas al inicio de la averiguación y de personas consignadas en temas de vida silvestre (Gráfica 2). El delito clasificado como "otros delitos de biodiversidad" tuvo más acciones realizadas (Gráfica 3) (4,240 averiguaciones previas, 3,018 persona detenidas al inicio y 2,542 personas consignadas dentro de las averiguaciones). El segundo delito con más acciones fue por violaciones al artículo 420, fracciones IV o V del CPF (1,104 averiguaciones previas, 1,487 personas detenidas y 1,318 personas consignadas), relacionadas con actividades en el tráfico de vida silvestre (captura, posesión, transporte y daño, por ejemplo). El delito con menos acciones fue por violaciones al artículo 415, párrafo último (relacionado con desarrollar actividades humanas que dañan la vida silvestre) (Gráfica 3), con sólo una averiguación previa iniciada.

Gráfica 2. Tendencia de averiguaciones previas iniciadas, personas detenidas al inicio y consignadas dentro de averiguaciones en delitos contra la vida silvestre del 2006 al 2018

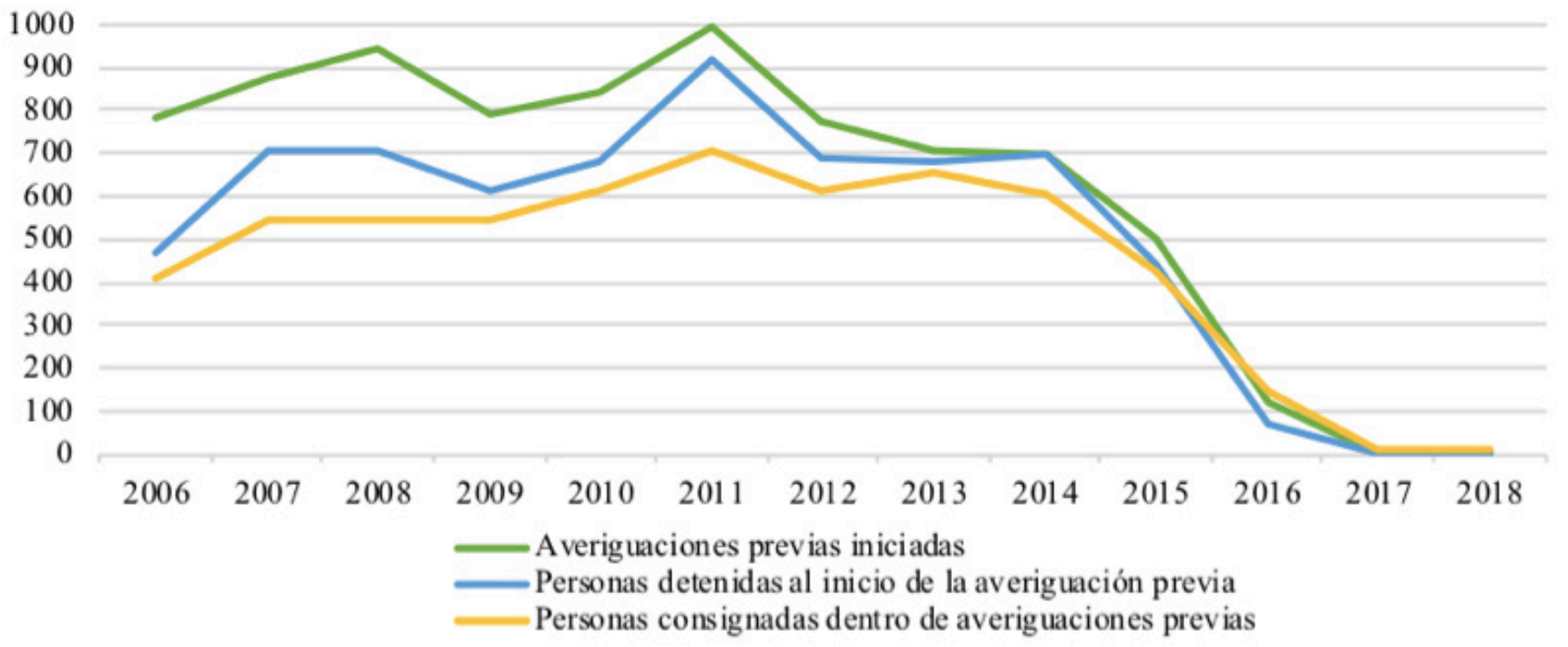

Fuente: los autores 
Gráfica 3. Esfuerzos en averiguaciones previas, personas detenidas y consignadas dentro de averiguaciones acumulado entre el 2006 y 2018, por artículo

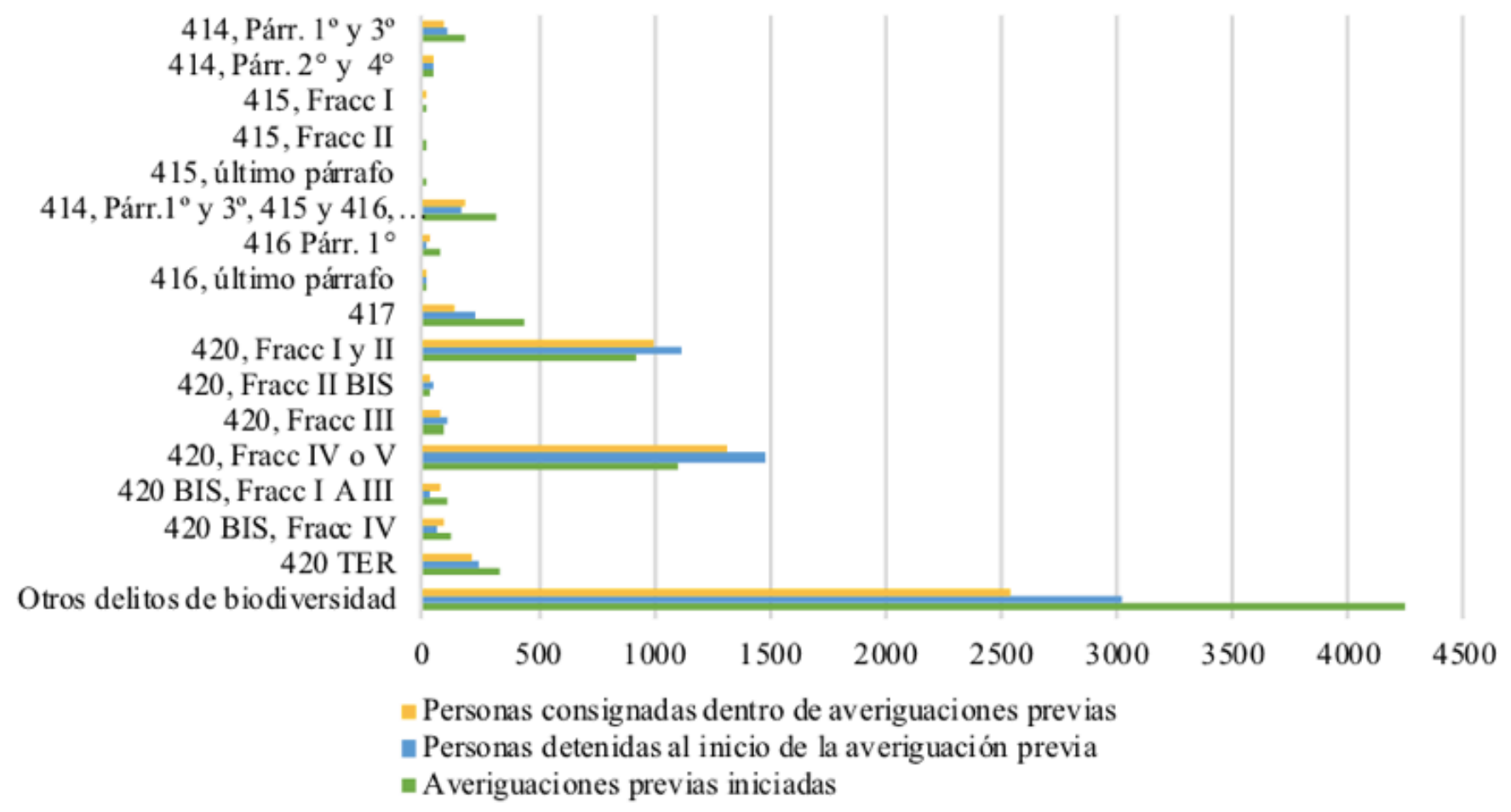

Fuente: los autores

Sobre la distribución de las frecuencias por entidad federativa en México, el estado con la frecuencia más alta de averiguaciones registradas fue jalisco, con 755 averiguaciones. Mientras que el estado con menor frecuencia fue Coahuila con 26 (Figura 1). La mayoría de las averiguaciones previas en vida silvestre se registran en el centro y sur del país (Figura 1), zonas conocidas por su diversidad biológica, principalmente en el sur, y por su crecimiento industrial, principalmente en el centro.

Al comparar la cantidad de personas detenidas al inicio de la averiguación y las personas consignadas (Figuras 2), la entidad con más personas detenidas y consignadas es Sinaloa (de color más oscuro, Figuras 2.a y 2.b) (572 personas detenidas y 565 consignadas en total del 2006 al 2018). La entidad no se caracteriza por su riqueza de especies, pero está en la zona critica del tráfico de Totoaba (Totoaba macdonaldi) considerada en México como una especie en "peligro de extinción" por la NOM-059-SEMARNAT-2010, se encuentra en el Apéndice I de la CITES y en la Lista Roja de Especies Amenazadas de la Unión Internacional para la Conservación de la Naturaleza (IUCN, por sus siglas en inglés), y su alta demanda en el mercado internacional ha llevado a su pesca ilegal y tráfico (Gobierno de México, 2019).

Por otra parte, la entidad con menos personas detenidas al inicio de la averiguación fue Coahuila, con 12 personas detenidas (Figura 
2.a), y la entidad con menos personas menos averiguaciones previas. Se aprecia que, consignadas fue Zacatecas, con 7 personas así como en las averiguaciones previas, es en consignadas (Figura 2.b). Condiciendo esas el centro y sur de México donde más personas dos últimas entidades en ser las que tienen detenidas y consignadas ha habido.

Figura 1. Averiguaciones previas penales por delitos en vida silvestre (acumulado del 2006 al 2018)

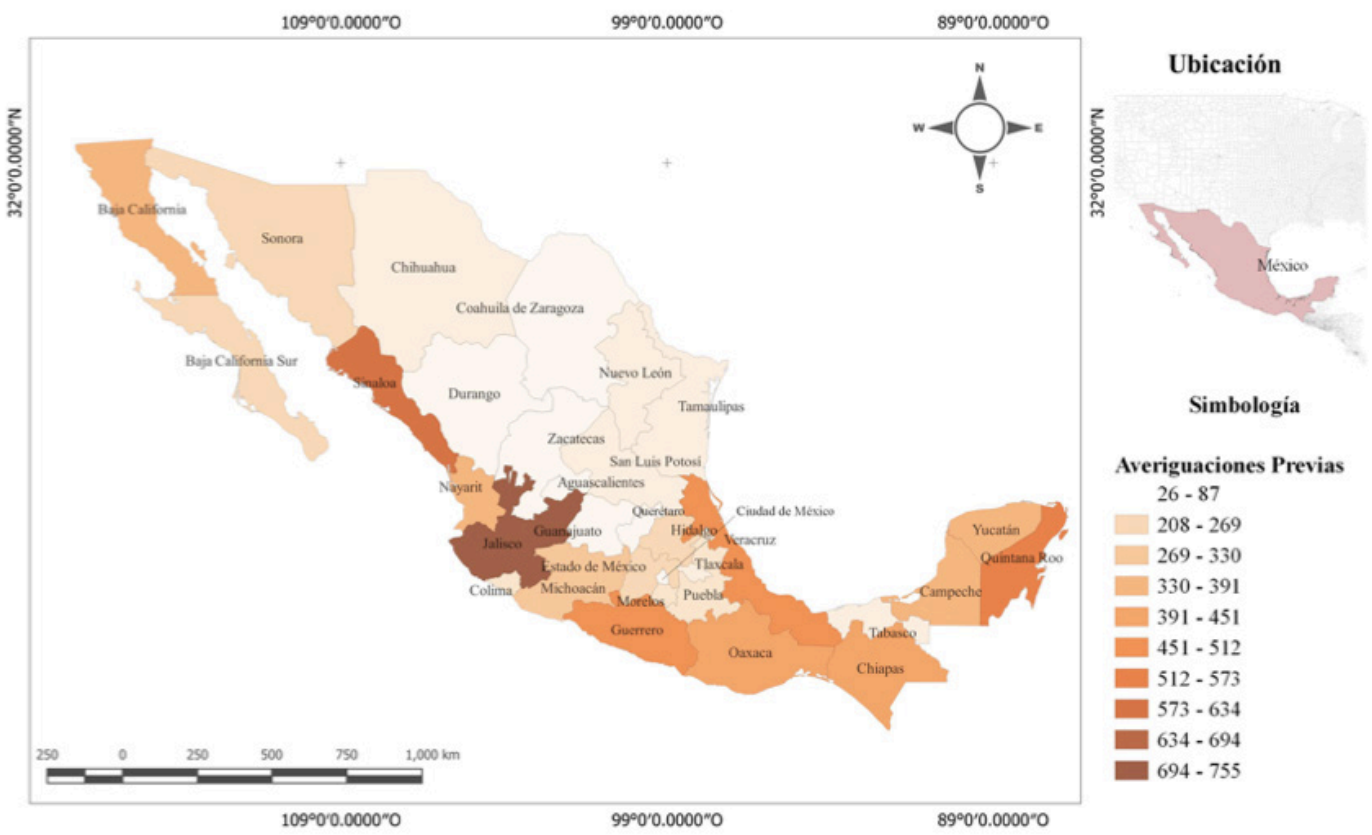

Fuente: los autores con información de obtenida según la LFTAI (2017).

Figura 2. Personas detenidas y consignadas por delitos en vida silvestre (acumulado del 2006 al 2018)
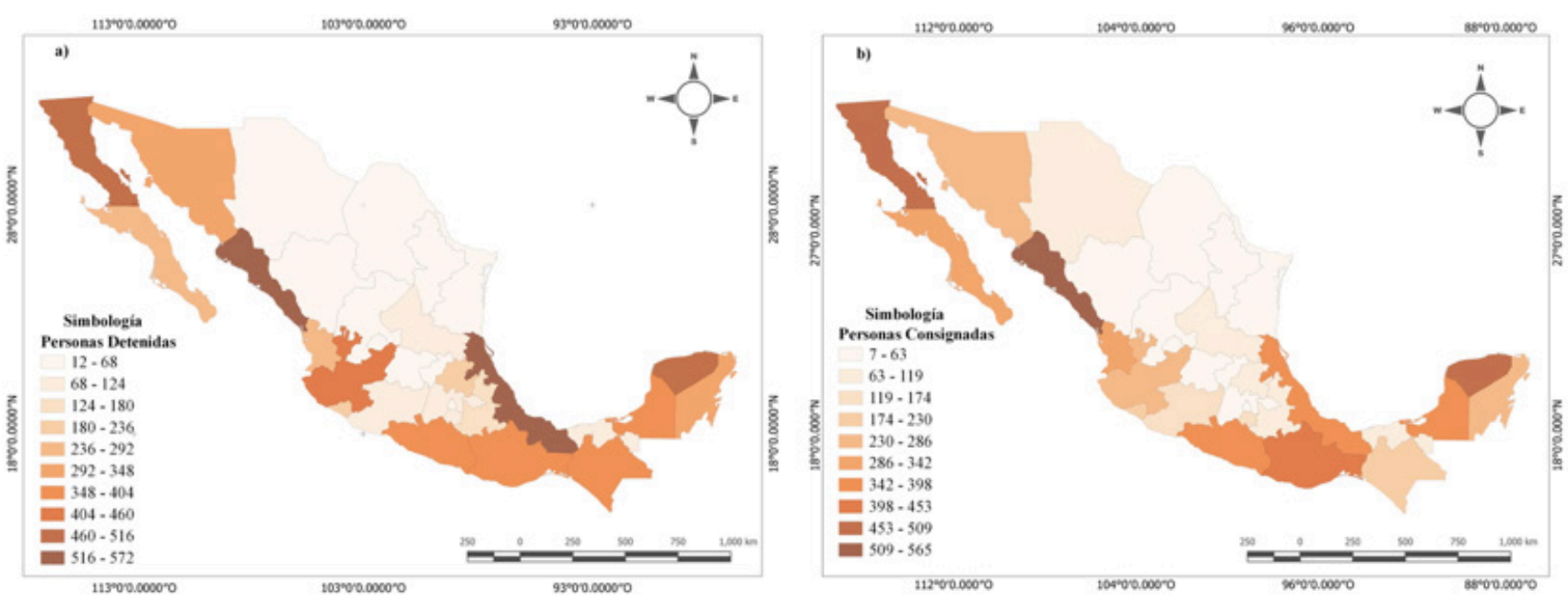

Fuente: los autores con información de obtenida según la LFTAI (2017). 
Esfuerzo de aplicación de la ley administrativa

En el sistema administrativo, entre el 2006 y 2019 , se realizaron 26,325 inspecciones y 4,902 operativos en vida silvestre, y se realizaron 6,241 inspecciones y 3,324 operativos en recursos marinos. Por lo que la autoridad mexicana realiza más inspecciones en vida silvestre, por encima de inspecciones en recursos marinos y operativos en los temas. Las inspecciones son las acciones que tienen más posibilidades de deslindar responsabilidades legales por crímenes contra la vida silvestre, al estar directamente relacionadas con la aplicación de la ley. En total, se realizaron 32,566 inspecciones en vida silvestre, que son poco más del $75.0 \%$ del total de averiguaciones previas en lo penal en vida silvestre durante el mismo periodo $(\mathrm{n}=$
8,044). Por lo que la mayoría de las acciones de aplicación de la ley en vida silvestre realizadas en México son administrativas, y que, a pesar de existir la obligación legal de colaboración entre instituciones, no se reflejan en la práctica. La Gráfica 4 presenta los esfuerzos en inspecciones y operativos, en vida silvestre y recursos marinos, realizados por la autoridad administrativa (PROFEPA) entre el 2006 y 2019. Así como ocurrió con las averiguaciones previas, se aprecian tendencias a la baja en la aplicación de la ley administrativa en vida silvestre. Entre el 2011 y 2012 comenzó un decremento anual casi constante en inspecciones y operativos en vida silvestre, hasta el 2019 aumenta de nuevo un poco. Además, como ocurrió en lo penal, en los años 2009 y 2011 fue en los que se realizaron más inspecciones y operativos.

Gráfica 4. Esfuerzo en inspecciones y operativos en vida silvestre y recursos marinos realizados entre el 2006 y 2019

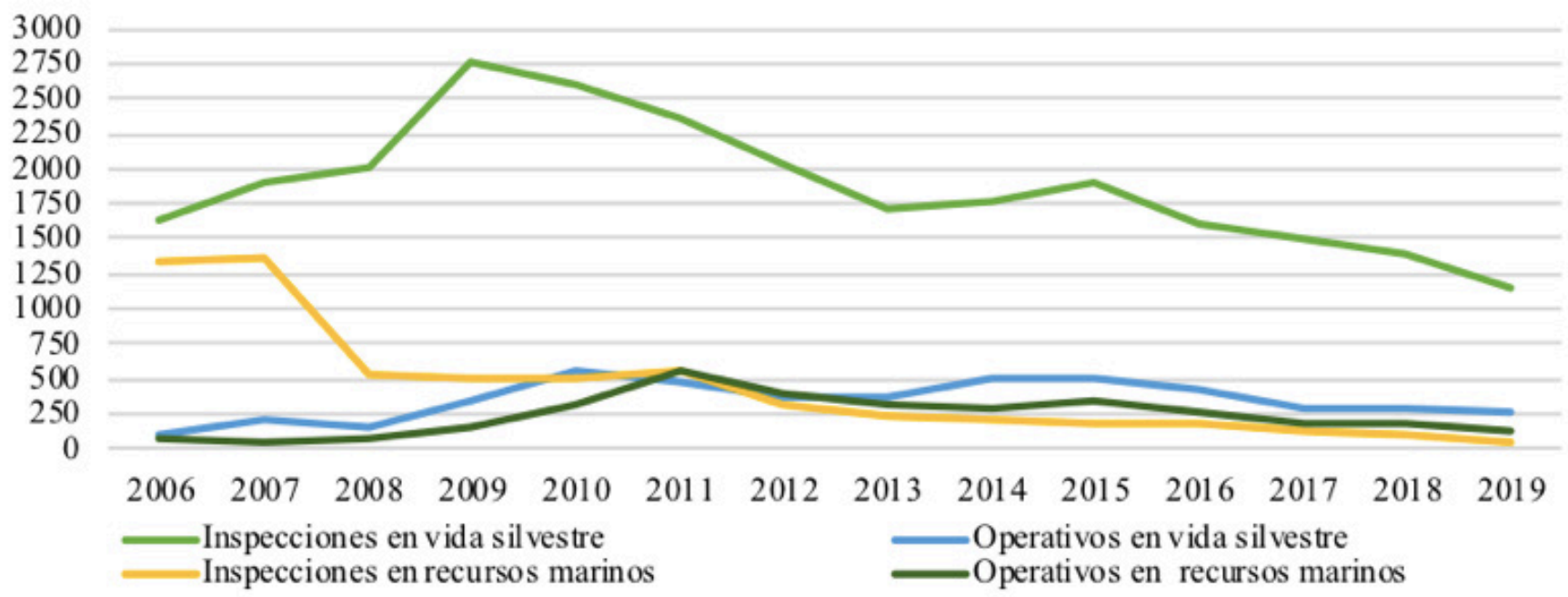

Fuente: los autores con información de obtenida según la LFTAI (2017).

Sobre la capacidad de personal de aplicación, entre el 2006 y 2019, hubo 289 inspectores, en promedio por año, en todo el país para aplicar la ley administrativa. Número de inspectores que además deben aplicar la ley en otras materias (forestal, impacto ambiental y cambio de uso de suelo), situación que limita la capacidad de respuesta de aplicación. Del 2016 al 2017 
el número de inspectores decreció de manera considerable, de 313 a 198; posteriormentea 191 en 2018 y 186 en 2019. Lo que podría explicar la disminución de acciones de aplicación de la ley durante esos años. Al disminuir el personal, disminuyó la aplicación de la ley por la poca capacidad de respuesta. Los esfuerzos de aplicación presentados en la Grafica 4 traen diversos resultados, como el aseguramiento de ejemplares vivos, de productos y subproductos de vida silvestre (Gráfica 5).

Gráfica 5. Aseguramiento de especímenes y productos y subproductos de vida silvestre producto de las inspecciones del 2006 al 2019

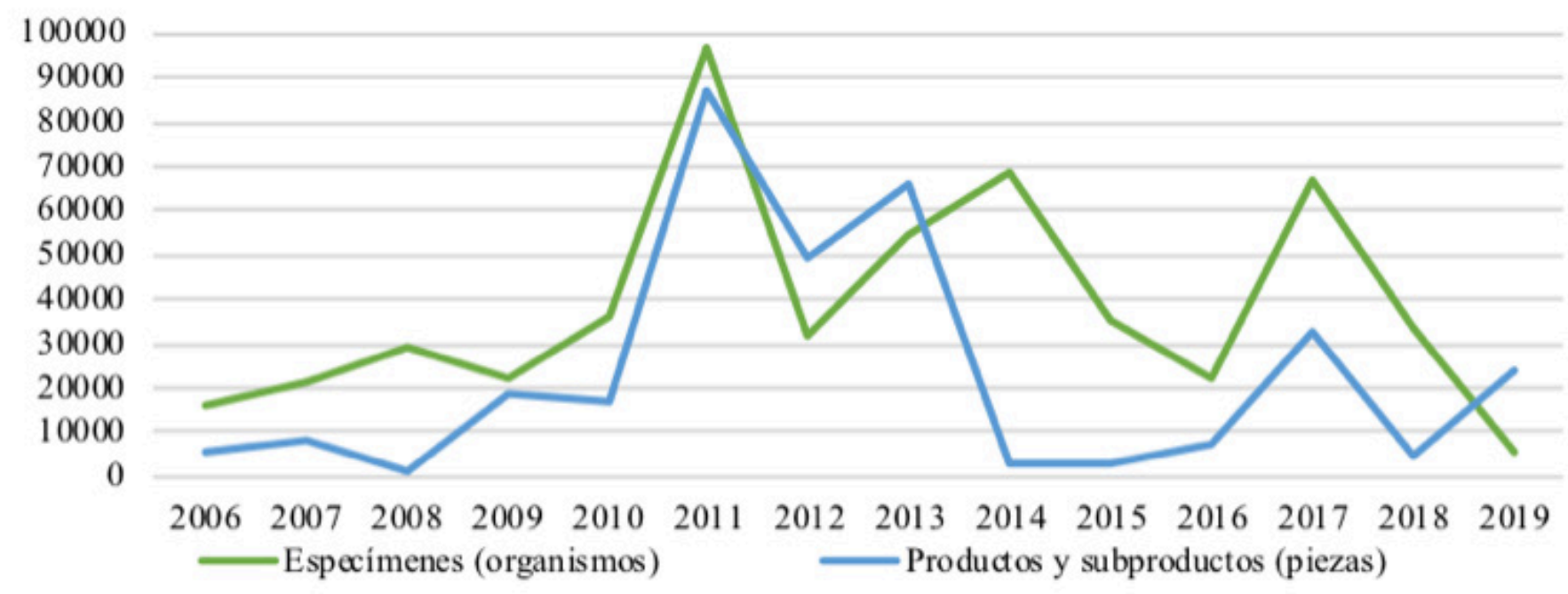

Fuente: los autores con información de obtenida según la LFTAI (2017).

Entre el 2006 y 2019 fueron asegurados precautoriamente 540,747 ejemplares vivos de vida silvestre y 326,503 productos y subproductos durante las visitas de inspección administrativas. En el 2011 fue cuando más ejemplares, productos y subproductos se aseguraron, además, fue uno de los años en los que más inspecciones se realizaron. Por lo tanto, el número de inspecciones realizadas por la autoridad administrativa está relacionado con la cantidad de especies aseguradas. Otra actividad administrativa que aporta al aseguramiento de especies es la inspección a zoológicos (Cuadro 4), actividad que no se realiza en lo penal.
La aplicación de la ley a estas instituciones trae como resultados ejemplares verificados y asegurados. No obstante, se aprecia una disminución de supervisión de la ley en zoológicos, con inspecciones fluctuantes en el periodo analizado, más en los últimos años y que coincide con la disminución de inspectores. Situación que se refleja en el número de ejemplares vivos y productos verificados y asegurados y que están relacionados con la protección de especies. La aplicación de la ley en los zoológicos no es constante, y ha estado en los últimos años en el debate entre académicos y movimientos sociales. 
Cuadro 4. Inspecciones a zoológicos y aseguramientos del 2009 al 2019

\begin{tabular}{cccccc}
\hline & $\begin{array}{c}\text { Zoológicos } \\
\text { inspeccionados }\end{array}$ & $\begin{array}{c}\text { Ejemplares } \\
\text { verificados }\end{array}$ & $\begin{array}{c}\text { Productos } \\
\text { inspeccionados }\end{array}$ & $\begin{array}{c}\text { Ejemplares } \\
\text { asegurados }\end{array}$ & $\begin{array}{c}\text { Productos } \\
\text { asegurados }\end{array}$ \\
\hline $\mathbf{2 0 0 9}$ & 56 & 25,418 & 307 & 3,042 & 307 \\
\hline $\mathbf{2 0 1 0}$ & 20 & 2183 & 0 & 290 & 0 \\
\hline $\mathbf{2 0 1 1}$ & 6 & 452 & 0 & 260 & 0 \\
\hline $\mathbf{2 0 1 2}$ & 2 & 465 & 0 & 211 & 0 \\
\hline $\mathbf{2 0 1 3}$ & 0 & 0 & 0 & 0 & 0 \\
\hline $\mathbf{2 0 1 4}$ & 17 & 103 & 38 & 71 & 38 \\
\hline $\mathbf{2 0 1 5}$ & 46 & 9,288 & 432 & 2,746 & 432 \\
\hline $\mathbf{2 0 1 6}$ & 49 & 11,451 & 57 & 1,440 & 29 \\
\hline $\mathbf{2 0 1 7}$ & 1 & 352 & 0 & 352 & 0 \\
\hline $\mathbf{2 0 1 8}$ & 3 & 489 & 0 & 186 & 0 \\
\hline $\mathbf{2 0 1 9}$ & 6 & 282 & 0 & 0 & 0 \\
\hline
\end{tabular}

Fuente: los autores con información de obtenida según la LFTAI (2017).

En la aplicación de la ley administrativa en vida silvestre (terrestre y marina) por entidad federativa (Figura 3), Tlaxcala fue donde menos inspecciones se realizaron entre el 2006 y 2019 , 198 inspecciones. Ese estado se caracteriza por tener el menor número de inspectores en todo el país y por estar entre los dos primeros lugares con menor riqueza de especies de vertebrados registradas, 417 especies. La zona con más inspecciones en donde se aplicó la ley fue en la Ciudad de México, junto con la Zona
Metropolitana del Valle de México, con 5,061 inspecciones durante el periodo. Eso puede estar relacionado a que, en esa zona, si bien no se caracteriza por si diversidad de especies, ahí es donde se ubican las oficinas centrales de PROFEPA, y a nivel nacional, cuenta con el mayor número de personal para aplicar la ley y es una zona estratégica del país para la distribución de mercancías y para el comercio, al ser el centro político, cultural y financiero en México. 
Figura 3. Inspecciones administrativas en vida silvestre (acumulado del 2006 al 2019)

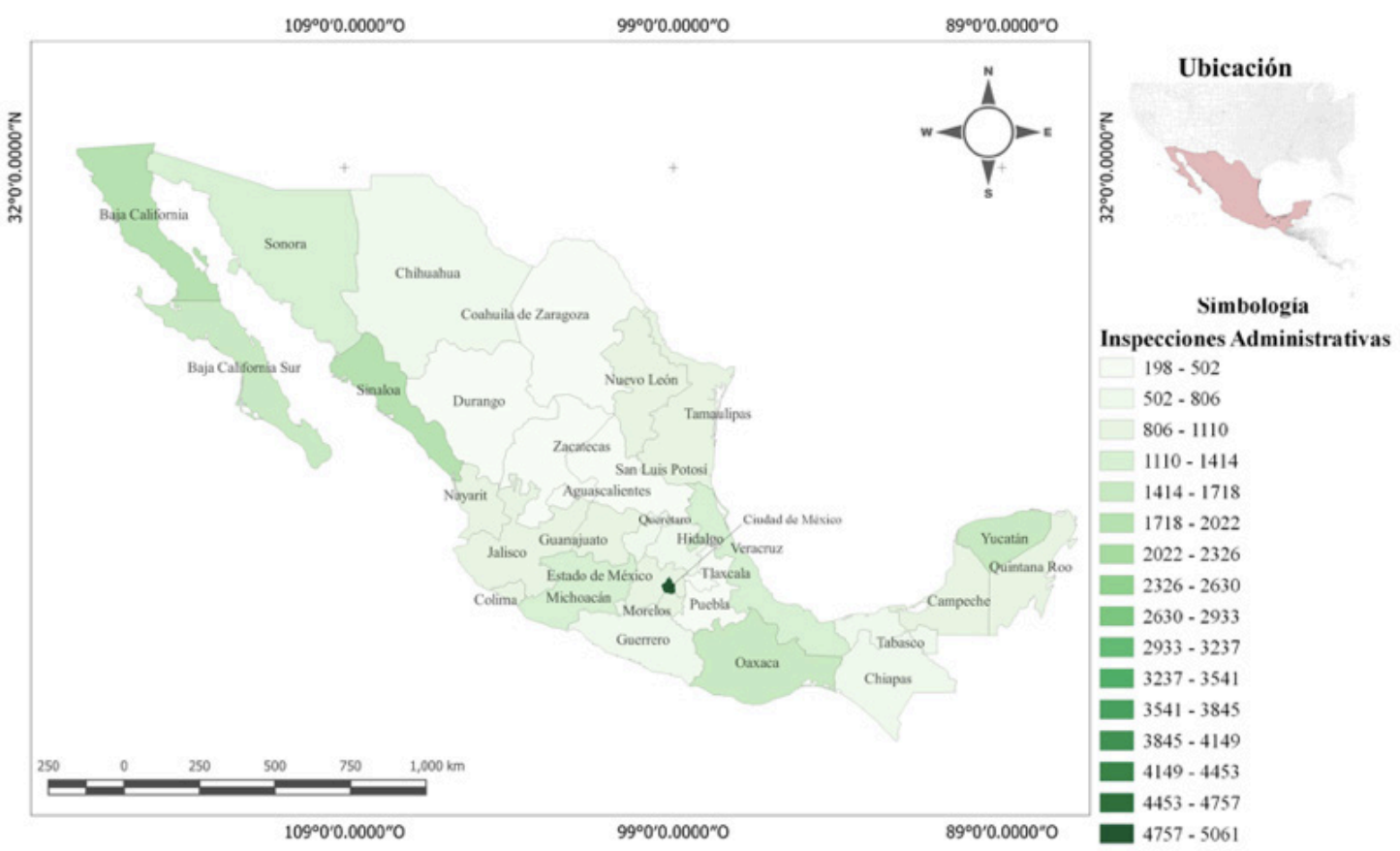

Fuente: los autores con información de obtenida según la LFTAI (2017).

Es en temas de vida silvestre "terrestre" (Figura 4.b), los cuatro estados con mayores donde más se aplica la ley, el 80.8 \% de las acciones de aplicación de la ley en recursos inspecciones son hacia ese rubro, muy por marinos se ubican en la región conocida por encima de las inspecciones en recursos marinos la distribución histórica natural de la Totoaba (Figura 4) con el $19.2 \%$ de la aplicación de la (Totoaba macdonaldi), el Golfo de California, ley. Podría deberse a que sólo hay 17 estados que, como se mencionó, es un tema central en costeros. Específicamente a recursos marinos México debido al tráfico ilegal de esa especie.

Figura 4. Comparativo entre inspecciones administrativas en vida silvestre "terrestre" y recursos marinos (acumulado del 2006 al 2019)
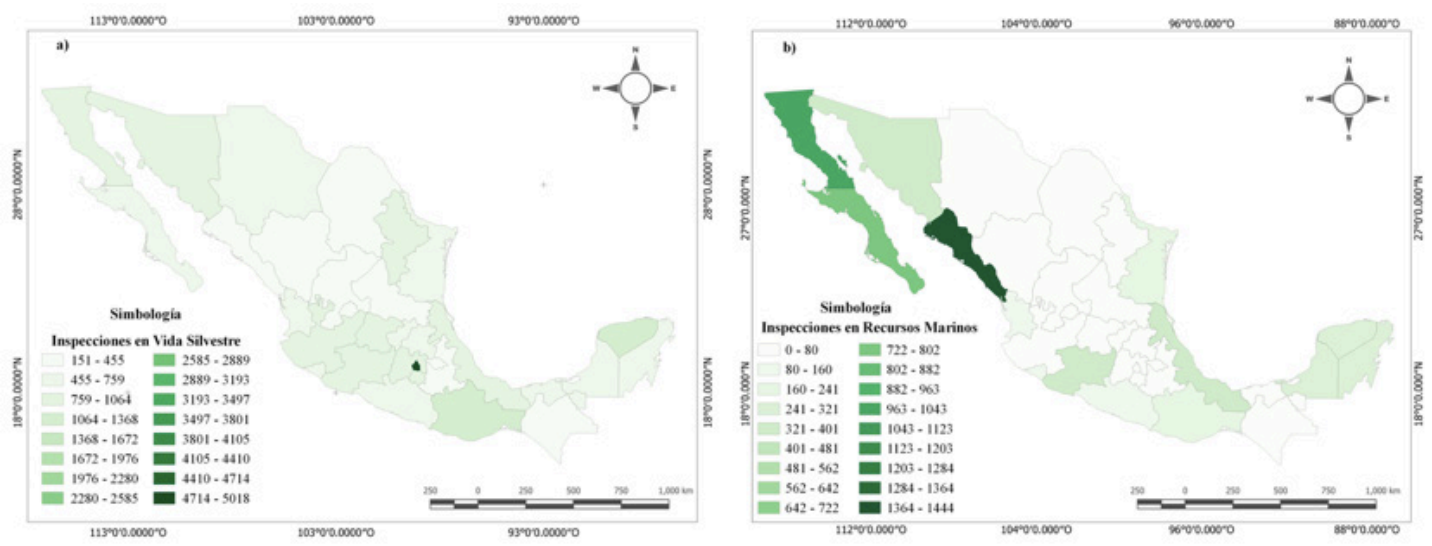

Fuente: los autores con información de obtenida según la LFTAI (2017). 
Al comparar la aplicación de lo penal y lo administrativo, las entidades en las que más se realizan inspecciones administrativas no son las que reportan el mayor número de averiguaciones previas en lo penal. Además de que en la mayoría de las entidades el número de inspecciones administrativas es mayor que las averiguaciones penales. Sólo en un estado existe un mayor número de averiguaciones penales $(n=580)$ respecto a las inspecciones administrativas $(n=438) . \mathrm{Ni}$ en la zona que registró la frecuencia más alta de inspecciones $(n=5,061)$ existe la mayor cantidad de averiguaciones penales, sólo tuvo 75 averiguaciones.

Figura 5. Inspecciones administrativas y averiguaciones previas penales en materia de vida silvestre del 2006 al 2019

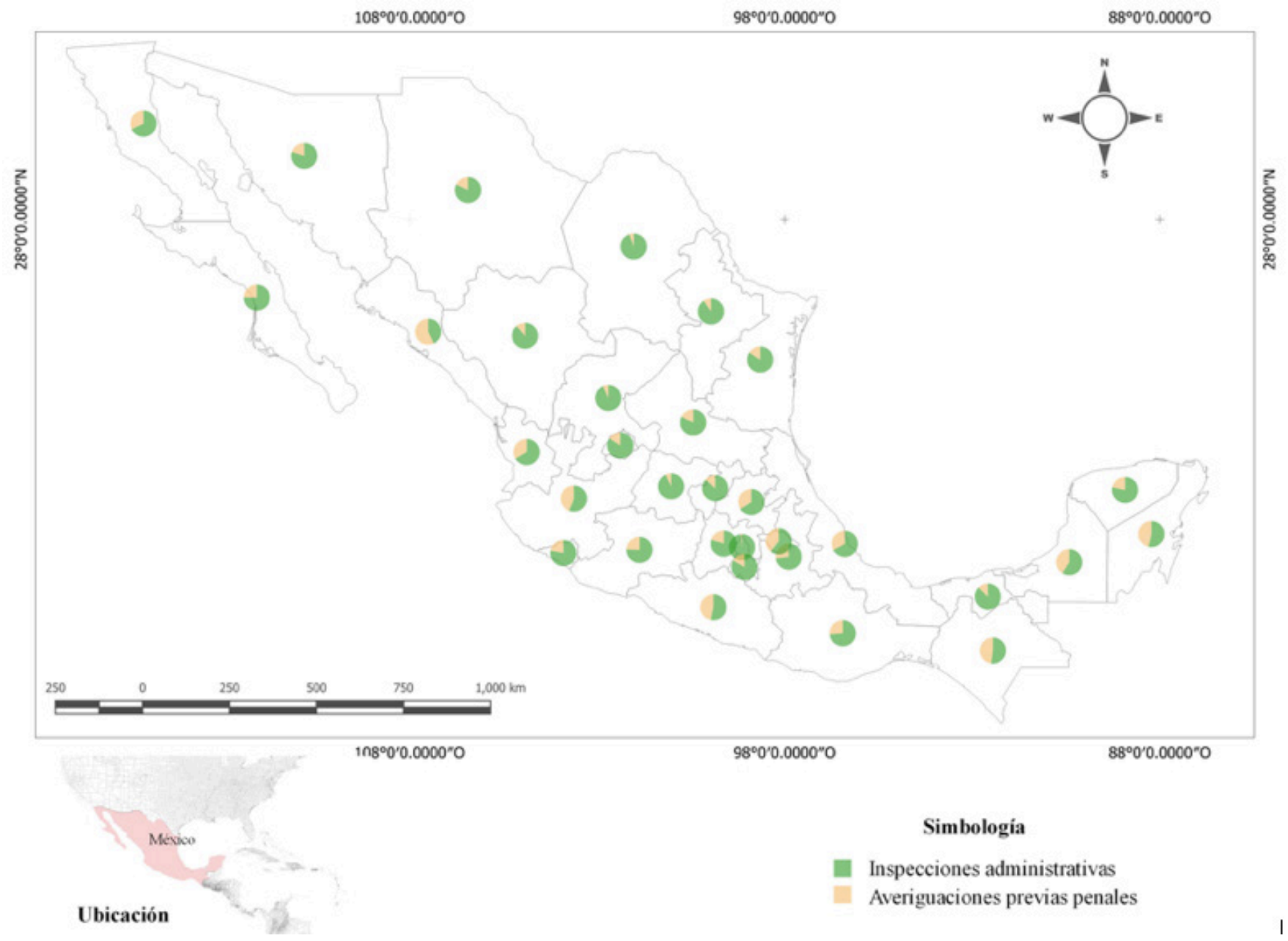

Fuente: los autores con información de obtenida según la LFTAI (2017). 
Por otra parte, en las entrevistas complementarias sobre la aplicación legal penal y administrativa en vida silvestre. Los inspectores mencionaron que cuando han trabajo en conjunto con las autoridades de seguridad pública (policías, agentes ministeriales, etc.), sobre todo federales, estos les han mencionado un desinterés por atender situaciones de vida silvestre. Con comentarios como "...a mi tráeme narcos, secuestradores, no animales o esas cosas ambientales..." (Inspector 1-PROFEPA, comunicación personal, 10 junio de 2018). Como indica la ley, los inspectores administrativos son requeridos por instituciones penales como apoyo para dictaminar sobre delitos en vida silvestre, pero las autoridades penales restan importancia su trabajo como inspectores. Les han dicho, por ejemplo, "a mi sólo dime si el delito que cometió es grave [por comercio de aves sin permiso, según el caso narrado], sino para sacarlo... urge sacarlo [al posible infractor] de los separos pues sólo está ocupando espacio" (Inspector 2-PROFEPA, comunicación personal, 19 mayo de 2019).

Los inspectores consideran que es un crimen grave en contra de la vida silvestre y los ecosistemas sacar especies de su hábitat natural o dañarlas, pero la ley administrativa se enfoca más "revisar los permisos, autorizaciones... que se cuente con este o aquel documento que autorice extraer o manipular ejemplares... pero no se valora el posible daño inmediato o futuro de la acción" (Inspector 3-PROFEPA, comunicación personal, 16 de octubre de 2018). Como si la ley administrativa estuviera más interesada en otorgar y revisar permisos que en prevenir o castigar los delitos contra la vida silvestre. Además, argumentan que los delitos ambientales no generan el mismo impacto en la población o en otras esferas institucionales como lo hacen otros delitos relacionados a la seguridad pública.

(...) los delitos ambientales aquí en el campo [campo profesional], sólo si es muy necesario o urgente nos reportan los casos, han sido pocas las veces que nos notifican las otras dependencias [policías estatales, federales, etc.] cuando hay algo, sólo atienden lo que es urgente o que Ilama mucho la atención pública (Inspector 4-PROFEPA, comunicación personal, 25 de abril de 2019).

En este sentido, los inspectores argumentan que las autoridades penales no tienen interés en los delitos contra la vida silvestre, y dan prioridad a otro tipo de delitos, sobre todo, aquellos denominados "delitos de alto impacto" que, por su alta incidencia, son riesgos latentes que conforman una sensación de vulnerabilidad social y de percepción de inseguridad, entre los que se encuentra el homicidio doloso, feminicidio, secuestro, extorsión, trata de personas, narcomenudeo; delitos que ocupan un lugar preponderante en la agenda pública para su atención (Observatorio Nacional Ciudadano, 2018).

Se muestra entonces, que en México la aplicación de la ley a través de inspecciones en vida silvestre es principalmente administrativa, superando las actuaciones en lo penal. Además, el predominio de la aplicación de la legislación ambiental desde el sistema administrativo muestra que el Estado no dimensiona las afectaciones de los delitos en escalas temporales 
y/o geográficas, lo cual, es coincidente con lo reportado por Nurse A., (2020) al establecer que los delitos ambientales tienen el potencial de causar un daño social y ambiental mucho más amplio y con consideraciones geográficas y temporales (Hall, M. y Varona, G., 2018, p. 114) distintas a otras manifestaciones criminales a las que se les considera de mayor impacto.

Al respecto, la discusión radica en que los delitos ambientales no cuentan con la misma atención por parte del Estado, lo cual, es coincidente con lo reportado también en otros estudios, en los se establece que estos delitos no ocupan un lugar justo en las agendas gubernamentales (como señala Moreto, W., 2015) y tampoco en los sistemas de justicia penal (como indica Nurse, A., 2020) derivado de que los delitos ambientales suelen ser percibidos como delitos de baja prioridad y por lo tanto no generan la respuesta requerida por los gobiernos al aplicar la ley y en los que "no hay víctimas" para reclamar sus derechos (O'Hear, M., 2004; Davies, C., et al., 2008; Skinnider, E., 2013; Castro-Salazar, J. y Luyando-Cuevas, J., 2020; Castro-Salazar, J. 2020; Nurse, A., 2020).

\section{CONCLUSIONES}

En México, las principales jurisdicciones en vida silvestre son de competencia federal, tanto el sistema penal como administrativo. Lo que limita a las autoridades estales y locales para actuar. Si bien en el Código Penal Federal penaliza delitos contra la vida silvestre, estos no superan los cinco artículos dedicados al tema y aunque las sanciones incluyen la privación de la libertad, es cierto que la mayoría de los esfuerzos de aplicación de la ley en vida silvestre recaen en el sistema administrativo, en el que las sanciones se enfocan a multas, suspensión de actividades o revocación de autorizaciones, incluso se pueden sancionar con "llamados de atención". De ese modo, los criminales ambientales generalmente reciben sanciones económicas o suspensiones de permisos por las faltas cometidas, pese a los impactos negativos a la vida silvestre y ecosistemas generados. En México, los delitos considerados de "alto impacto social" tienen un lugar preponderante frente a aquellos relacionados con la vida silvestre, pese a que los daños causados en estos delitos pueden tener consecuencias duraderas e irreversibles que ponen en riesgo también la seguridad humana.

Los estados con más especies registradas en su territorio pueden tener menos acciones de aplicación de la legislación, penal y administrativa, que entidades con menos especies. Sólo en casos polémicos, que incluso son foco de atención de medios y organizaciones internacionales, se observó mayor interés por las autoridades para aplicar las leyes ambientales en esas zonas, tanto administrativas como penales. Se observó una relación entre el número de inspectores administrativos y el número de acciones realizadas, la actuación del Estado hacia crímenes de vida silvestre está en función al capital humano destinado a atenderlos.

Aunado a las sanciones laxas, la aplicación de la ley administrativa no siempre se traduce en proceso penales, pese a que la misma ley exhorta a las autoridades administrativas a colaborar y denunciar en lo penal. Lo que podría interpretarse como una falta de colaboración entre las dos principales instituciones que 
sancionan los delitos y crímenes contra la vida silvestre. Además, se identificó que las acciones de inspecciones administrativa $y$ penal no se realizan de manera constante, ni van incrementando conforme pasan los años, al observarse intervalos fluctuantes, sobre todo decrecientes, en los esfuerzos de aplicación de la legislación. Es necesario mejorar las acciones de colaboración entre las instituciones, la eficaz aplicación de la legislación ambiental y optar por acciones legales de prevención de delitos contra la vida silvestre, no solamente buscar acciones reactivas.

\section{TRABAJOS CITADOS}

Allenby, R. (2000). Environmental Security: Concept and Implementation. International Political Science Review, 21(1): 5-21. https://doi.org/10.1177/0192512100211001

Ayling, J. (2017). "Prevention of transnational environmental crime and regulatory pluralism". In P. Drahos (Ed.), Regulatory Theory: Foundations and applications (pp. 499-516). Australia. ANU Press. https://doi.org/10.22459/ RT.02.2017.29

Barrett, S. y White, R. (2017). Disrupting environmental crime at the local level: an operational perspective. Palgrave Communications, 3(2): 1-8. https://doi.org/10.1057/s41599017-0006-3

Bellew, S. y Surtz, D. (1997). Criminal Enforcement of Environmental Laws: A Corporate Guide to Avoiding Liability. Villanova Law Enviromental Law Journal, 8(1): 2052035. https://digitalcommons.law.villanova.edu/elj/vol8/ iss $1 / 5 /$

Boratto, R. y Gibbs, C. (2019). Advancing interdisciplinary research on illegal wildlife trade using a conservation criminology framework. European Journal of Criminology, 1-22. https://doi.org/10.1177/1477370819887512
Brisman, A. y South, N. (2012). A green-cultural criminology: An exploratory outline. Crime Media Culture, 9(2): 115135. https://doi.org/10.1177/1741659012467026

Castro-Salazar, J. y Luyando-Cuevas, J. (2020). Evaluación de la actividad de inspección de recursos forestales en México. Textual, 75: 11-35. https://doi.org/10.5154/r. textual.2019.75.01

Castro-Salazar, J. (2021). Gobernanza forestal, análisis desde la accesibilidad geográfica de la Procuraduría Federal de Protección al Ambiente a zonas forestales de México. Intersticios sociales, 351-373. http://www. intersticiossociales.com/index.php/is/article/view/341

Carpio-Domínguez, J., Vargas-Orozco, C., Villarreal, K. y Meraz, M. (2018a). Las redes sociales como factor criminógeno de la venta ilegal de especies en Tamaulipas (México): el caso de Facebook. CienciaUAT, 13(1): 19-34. https://revistaciencia.uat.edu.mx/index.php/CienciaUAT/ article/view/972/434

Carpio-Domínguez, J., Vargas-Orozco, C. Villarreal-Sotelo, K., Santillana-Cantú, R. y Hernández-Rodríguez, I. (2018b). Percepción Criminológica de la Posesión de Animales por el Narcotráfico en Tamaulipas, el Zoológico del Crimen Organizado. Letras Jurídicas, 26: 1-18.

Carpio-Domínguez, J. (2021). Crimen Organizado (narcotráfico) y conservación ambiental: el tema pendiente de la seguridad pública en México. Revista CS, 33: 237-274. https://doi. org/10.18046/recs.i33.4076

Chávez, B. F. (2009). Derecho Al Medio Ambiente. Un Derecho Convergente. CEJA, 1-19. http://www.ceja.org.mx/IMG/ pdf/DERECHO_AMBIENTAL_CONVERGENTE_NUEVA_ redaccion.pdf

Elliott, L. (2007). Transnational environmental crime in the Asia Pacific: ¿an 'un(der)securitized' security problem? The Pacific Review, 20(4): 499-522. https://doi. org/10.1080/09512740701671995

Debbie Banks,

Davies, C., Gosling, J., Newman, J., Rice, M., Wadley J. and Walravens, F. (2008). Environmental crime. A threat to our future. London, UK. Environmental Investigation 
Agency (EIA). https://globalinitiative.net/wp-content/ uploads/2017/12/EIA-Environmental-Crime-A-Threat-toOur-Future.pdf

Epstein, J. (1995). Law Enforcement Response to Environmental Crime. U.S. National Institute of Justice Pres. https://www. ojp.gov/pdffiles1/Digitization/151399NCJRS.pdf

European Network of Prosecutors for the Environment (ENPE). 2018. Sanctioning Environmental Crime (WG4) Prosecution and judicial practices. European Union. ENPE Press. https://eufje.org/images/DocDivers/18_LIFE-ENPE_WG4_ InterimReport_FINAL1.pdf

European Union Agency for Law Enforcement Cooperation (EUROPOL). (2015). Intelligence Project on Environmental Crime. Report on Environmental Crime in Europe. European Union. EUROPOL Press. http://www.envicrimenet.eu/ images/docs/ipec_report_on_environmental_crime_in_ europe.pdf

Fagan, M. (2017). Security in the anthropocene: Environment, ecology, escape. European Journal of International Relations, 23(2): 292-314. https://doi. org/10.1177/1354066116639738

Fang, L., Hipev, K. y Kilgour, D. (1994). "Enforcement of Environmental Laws and Regulations: A Literature Review". En K. W. Hipel (ed.), Stochastic and Statistical Methods in Hydrology and Environmental Engineering (pp. 3-15). Netherlands. Springer Press. https://doi.org/10.1007/97894-017-3081-5_1

Flick, U. (2015). El diseño de la investigación cualitativa. Madrid. Morata editorial. https://dpp2017blog.files.wordpress. com/2017/08/disec3b1o-de-la-investigacic3b3ncualitativa.pdf

Floyd, R. (2008). The Environmental Security Debate and its Significance for Climate Change. The International Spectator, 43(3): 51-65. https://doi.org/10.1080/03932720802280602

Gibbs, C., Gore, M., McGarrell, E. y Rivers, L. (2010). Introducing Conservation Criminology: Towards Interdisciplinary Scholarship on Environmental Crimes and Risks. The British Journal of Criminology, 50(1): 124-144. https://doi. org/10.1093/bjc/azp045
Gibbs, C., McGarrell, E. y Sullivan, B. (2015). Intelligence-led policing and transnational environmental crime: A process evaluation. European Journal of Criminology, 12(2): 242259. https://doi.org/10.1177/1477370815571947

Gobierno de México. (2019). Pez Totoaba: el pez más grande del Alto Golfo. Procuraduría Federal de Protección al Ambiente (PROFEPA). https://www.gob.mx/profepa/articulos/peztotoaba-el-pez-mas-grande-del-alto-golfo

Hall, M. y Varona, G. (2018). La victimología verde como espacio de encuentro para repensar la otredad más allá de la posesión. Revista de Victimología, (7): 107-128. https:// doi.org/10.12827/RVJV.7.04

Hall, M. (2014). The roles and use of law in green criminology. International Journal for Crime, Justice and Social Democracy, 3(2): 96-109. https://doi.org/10.5204/ijcjsd. v3i2.176

Horne, D. (2013). Policy responses to transnational wildlife crime in the asia-pacific. Part 1: global and regional policy context and a potential framework for optimal national policy. Transnational Environmental Crime Project, Working Paper. Australia. Australian National University Press. http:// ips.cap.anu.edu.au/sites/default/files/IPS/IR/TEC/TEC_ Working_Paper_Part\%20 1_2013_PolicyResponses_to_ Transnational_Wildlife_Crime_in_the_Asia-Pacific.pdf Instituto Nacional de Estadística y Geografía (INEGI). Encuesta Nacional de Victimización y Percepción sobre Seguridad Pública (ENVIPE) 2020. Principales resultados en Tamaulipas. México. INEGI. https://www.inegi.org. mx/contenidos/programas/envipe/2020/doc/envipe2020_ tamps.pdf

Jaffe, L. (1963). The Judicial Enforcement of Administrative Orders. Harvard Law Review, 76(5): 865-928. https://doi. org/10.2307/1338516

López, P. L. y Ferro, A. (2006). Derecho ambiental. México. IURE editores.

Lynch, M. (2018). County-Level Environmental Crime Enforcement: A Case Study of Environmental/Green Crimes in Fulton County, Georgia, 1998-2014. Deviant Behavior. 1-15. https://doi.org/10.1080/01639625.2018.1461746 
Lynch, M. (2019). Green Criminology and Environmental Crime: Criminology That Matters in the Age of Global Ecological Collapse. Journal of White Collar and Corporate Crime, 1(1): 50-61. https://doi.org/10.1177/2631309X19876930

Massé, F. (2019). Conservation Law Enforcement: Policing Protected Areas. Annals of the American Association of Geographers, 110(3): 758-773 https://doi.org/10.1080/246 94452.2019.1630249

Massé, F., Dickinson, H., Margulies, J., Joanny, L., LappeOsthege, T. y Duffy, R. (2020). Conservation and crime convergence? Situating the 2018 London Illegal Wildlife Trade Conference. Journal of Political Ecology, 27(1): 23-42. https://doi.org/10.2458/v27i1.23543

Maxwell, J. (1992). Understanding and Validity in Qualitative Research. Harvard Educational Review, 62(3): 279-301. https://doi.org/10.17763/haer.62.3.8323320856251826

Maxwell, S. y Maxwell, C. (2020). Ecology and criminology? Applying the tenets of procedural justice on compliance to environmental regulations. Criminology \& Criminal Justice, 1-18. https://doi.org/10.1177/1748895820922291

McGarrell, E. y Gibbs, C. (2014). Conservation Criminology, Environmental Crime, and Risk: An Application to Climate Change. Oxford Handbooks Online, 1-33. https://doi. org/10.1093/oxfordhb/9780199935383.013.54

Moreto, W. (2015). Introducing intelligence-led conservation: bridging crime and conservation science. Crime Science, 4(1): 1-11. https://doi.org/10.1186/s40163-015-0030-9

Nellemann, C., Henriksen, R., Kreilhuber, A., Stewart, D., Kotsovou, M., Raxter, P., Mrema, E. y Barrat, S. (2016). The rise of environmental crime: A growing threat to natural resources peace, development and security. UNEP Press.

Nellemann, C., Henriksen, R., Pravettoni, R., Stewart, D., Kotsovou, M., Schlingemann, M.A.J., Shaw, M. y Reitano, T. (2018). World Atlas of Illicit Flows. RHIPTO-INTERPOLGl Assessment Press. https://globalinitiative.net/wp-content/ uploads/2018/09/Atlas-IIlicit-Flows-FINAL-WEB-VERSIONcopia-compressed.pdf

Nilsson, A. (2011). Enforcing Environmental Responsibilities. A Comparative Study of Environmental Administrative Law.
Sweden. Uppsala Universitet Press. http://www.diva-portal. org/smash/get/diva2:411546/FULLTEXT01.pdf

Nurse, A. (2020). Contemporary Perspectives on Environmental Enforcement. International Journal of Offender Therapy and Comparative Criminology, 1-18. https://doi. org/10.1177/0306624X20964037

Observatorio Nacional Ciudadano. (2018). Reporte sobre delitos de alto impacto 2018. Observatorio Nacional Ciudadano. https://onc.org.mx/publicaciones

O'Hear, M. (2004). Sentencing the Green-Collar Offender: Punishment, Culpability, and Environmental Crime. Journal of Criminal Law and Criminology, 95(1): 133-188. https:// ssrn.com/abstract=2469385

Penalva-Verdú, C., Alaminos-García, A., Francés-García, F. y Santacreu-Fernández, O. (2015). La investigación cualitativa, técnicas de investigación y análisis con ATLAS.ti. Ecuador. PYDLOS Ediciones. https://rua.ua.es/ dspace/bitstream/10045/52606/1/INVESTIGACION_ CUALITATIVA.pdf

Pink, G. (2013). Law enforcement responses to transnational environmental crime: choices, challenges, and culture. Transnational Environmental Crime Project, Working Paper. Australia. Australian National University Press. http://ir.bellschool.anu.edu.au/sites/default/files/ uploads/2016-09/tec_working_paper_4-2013.pdf

Rodríguez-Manzanera, L. (2015). Criminología. México. Porrúa editores.

Secretariado Ejecutivo del Sistema Nacional de Seguridad Pública. (2021). Datos Abiertos de Incidencia Delictiva. Gobierno de México. https://www.gob.mx/sesnsp/accionesy-programas/datos-abiertos-de-incidencia-delictiva

Skinnider, E. (2013). Effect, Issues and Challenges for Victims of Crimes that have a Significant Impact on the Environment. United Nations Office on Drugs and Crime. https://www. unodc.org/documents/commissions/CCPCJ/CCPCJ_ Sessions/CCPCJ_22/PNI_Workshop/Paper_ICCLR_CJP_PNIWorkshop.pdf

Sozzo, M. (2003). ¿Contando el delito? Análisis crítico comparativo de las Encuestas de Victimización en Argentina. 
Cartapacio de Derecho: Revista virtual de la Facultad de Derecho, 5: 1-143. http://www.pensamientopenal.com.ar/ system/files/2015/01/doctrina40378.pdf

Steinzor, R. 2016. How criminal law can help save the environment. Environmental Law, 46(1): 209-239. https:// digitalcommons.law.umaryland.edu/cgi/viewcontent. cgi?article $=2567 \&$ context=fac_pubs

Tsioumani, E. y Morgera, E. (2010). Wildlife legislation and the empowerment of the Poor in Asia and Oceania. Viet Nam. FAO Press. http://www.fao.org/3/au826e/au826e.pdf

White, R. (2007). Dealing with Environmental Harm: Green Criminology \& Environmental Law Enforcement. Tasmanian Institute of Law Enforcement Studies, (5): 1-8. https://www. utas.edu.au/_data/assets/pdf_file/0003/293745/Briefing_ Paper_No_5.pdf

White, R. (2010). "Transnational Environmental Crime". En M. Natarajan (Ed.), International Crime and Justice (pp. 193199). Cambridge. Cambridge University Press. https://doi. org/10.1017/CBO9780511762116.031

White, R. (2013). The Conceptual Contours of Green Criminology. En R. Walters et al. (Ed.), Emerging Issues in Green Criminology (pp. 17-33). London. Palgrave Macmillan Press. https://doi.org/10.1057/9781137273994_2

White, R. (2014). Green Criminology. Encyclopedia of Criminology and Criminal Justice, 1976-1984. https://doi. org/10.1007/978-1-4614-5690-2_314

Wyatt,T.(2014). "An assessment of media and partner engagement with the International Consortium on Combating Wildlife Crime". En E. Lorraine (Ed.), Transnational Environmental Crime Project: A Workshop Report Australia. Australian National University Press. http://ir.bellschool.anu.edu.au/ sites/default/files/uploads/2016-09/tec_workshop_report. pdf

\section{Jesús Ignacio Castro Salazar}

Afiliación: Tecnológico Nacional de México/Instituto Tecnológico Superior de Abasolo (TecNM/ITS de Abasolo)
Doctor en Ciencias Sociales con Orientación en Desarrollo Sustentable (UANL). Maestro en Administración Integral del Ambiente (El Colef). Ingeniero Ambiental (UG). Catedrático e investigador de licenciatura en el Tecnológico Nacional de México/ Instituto Tecnológico Superior de Abasolo. Correo electrónico: jicastro13@hotmail.com

\section{José Luis Carpio-Domínguez}

Afiliación: Unidad Académica Multidisciplinaria Reynosa Aztlán, Universidad Autónoma de Tamaulipas (UAMRA-UAT)

Doctorando en Ciencias Sociales con Orientación en Desarrollo Sustentable (UANL). Maestría en Criminología y Ciencias Forenses (UAT). Licenciatura en Criminología (UNO). Catedrático e investigador de licenciatura y posgrado en la Unidad Académica Multidisciplinaria Reynosa Aztlán de la Universidad Autónoma de Tamaulipas. Correo electrónico: jcarpio@docentes.uat.edu.mx

\section{Inés Arroyo-Quiroz}

Afiliación: Centro Regional de Investigaciones Multidisciplinarias, Universidad Nacional Autónoma de México (CRIM-UNAM).

Doctora en Gestión de la Biodiversidad (Universidad de Kent). Bióloga (UNAM). Miembro activo de los grupos de especialistas en Política Ambiental, Económica y Social de la Unión Mundial para la Naturaleza (UICN). Investigadora de tiempo completo del Centro Regional de Investigaciones Multidisciplinarias, Universidad Nacional Autónoma de México (CRIMUNAM). Correo electrónico: inesaq@crim.unam.mx 